\title{
iMath: Digital Images Modeled with Matrices
}

\author{
David A. Buhl (Corresponding author) \\ Mathematics Department, Northern Michigan University \\ Marquette, MI 49855, USA \\ Tel: 906-227-2089Ｅ-mail: dbuhl@nmu.edu \\ Joshua Thompson \\ Mathematics Department, Northern Michigan University \\ Marquette, MI 49855, USA \\ Sabrina Wheeler \\ Mathematics Department, Northern Michigan University \\ Marquette, MI 49855, USA
}

Received: October 22, 2014 Accepted: November 19, $2014 \quad$ Published: January 9, 2015

doi:10.5296/ire.v3i1.6884

URL: http://dx.doi.org/10.5296/ire.v3i1.6884

\begin{abstract}
This paper arms today's teachers of mathematics with a response to the age-old question, "What are matrices used for anyway?" Today's students spend much of their life consuming and producing digital media. Many of these students can read images and edit digital photographs with ease. We aim to capture student's interest in mathematics by showing how the images on computer screens, tablets, and smartphones are simply matrices of numbers and each color can be represented with just three numbers. Students gain both a new appreciation for color and for mathematics when learning to see color this way. We show how addition of colors can be thought of as addition of matrices and provide examples of numerical color addition in various color models. Armed with these simple ideas of how matrices underpin digital imagery, teachers can motivate students of the digital age to learn more mathematics.
\end{abstract}

Keywords: mathematics education, matrices, color, mathematics, digital imagery, RGB, 
mathematical modelling

\section{Introduction}

In contemporary society, visual imagery is highly prevalent. Students of the digital age are constantly bombarded with images and visual communication. Paul Martin Lester, professor of communications at California State University at Fullerton has written extensively about society's shift from using words to images, "Something is happening. We are becoming a visually mediated society. For many, understanding of the world is being accomplished, not through reading words, but by reading images” (Lester, 2006). This shift is important to recognize when teaching mathematics to contemporary students. Students' interest in digital imagery can also be used to model how mathematics "works" in their everyday lives.

By using student interest in digital imagery, this article explores the possibility of introducing matrices in the application of photo editing using the RGB color model, the color system for electronic screens. An initial explanation of how matrices can be used to model binary or Boolean images (meaning made up of only two colors black and white) is provided. We then progress to a mathematical explanation of more complex images including grayscale images (showing only shades of gray between white and black), monochromatic images (meaning made up of all the shades of one color), and finally to full, three layered color images made by the RGB color model. The key between understanding these visuals and the mathematical modeling are the matrices and their numerical inputs that create an image. By using the information in this article, students will have a better understanding of the role mathematics plays in making, displaying, and altering digital images.

\section{Visual Imagery}

For students, visual images are established and important. Through various social media sites including Facebook and Instagram, the editing and posting of photos has become an everyday activity for many students. Visual imagery is not only important through leisure mediums; it must also play a part in formal education due to the growing amount of visual-spatial learners in the younger generation. Visual-spatial learners are non-sequential learners that think in pictures rather than words. These learners are more likely to grasp the big picture rather than the specific details and have unique organizational methods (Kruger Silverman, 2013). A number of studies suggest an increase in visual-spatial learning preferences among students and yet these learners are falling behind in traditional mathematic classrooms where teaching memorization and sequential steps are the norm (Rapp, 2009). In order to engage these types of learners, it is extremely important to relate educational subjects to something visual and to show mathematical processes that can be seen.

\subsection{Boolean Images}

The connections between mathematics and visual culture are prevalent within the matrices that build images seen on computers and phones. How these images are viewed is based upon the RGB additive color model (RGB is an acronym for the primary colors of red, green and blue used in the model) of which matrices are pivotal. "Felix the Cat" (Figure 1) is an example of a binary image or Boolean image meaning that it is made up of only two colors, 


\section{I Macrothink}

black and white (Bortolossi and Pesco).

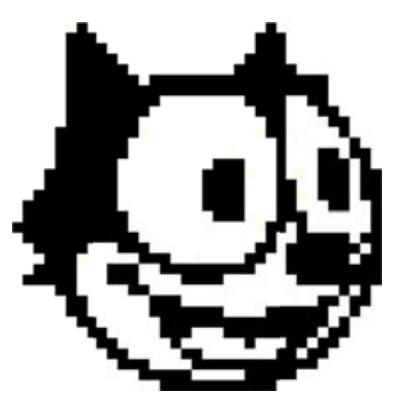

Figure 1. Felix the Cat

This digital image can be represented by a square matrix ( $\mathrm{n} \mathrm{x} n$ ) using 0 s and $1 \mathrm{~s}$ to represent black and white respectively. Each matrix input of 0 or 1 represents the information of one pixel of the original image. The size (n) of the matrix determines the resollution of the image. Figure 2 illustrates the digital image of Felix the Cat represented by a 35 x 35 matrix using 0s and 1 s to represent black and white respectively. By comparing Figure 1 with Figure 2, we notice the image is very "pixilated" or better said, the individual edges of each individual square pixel within the image can be seen, and thus the overall image is less smooth. The more pixels, or matrix input values, an image has, the bigger the matrix and the smoother the image becomes.
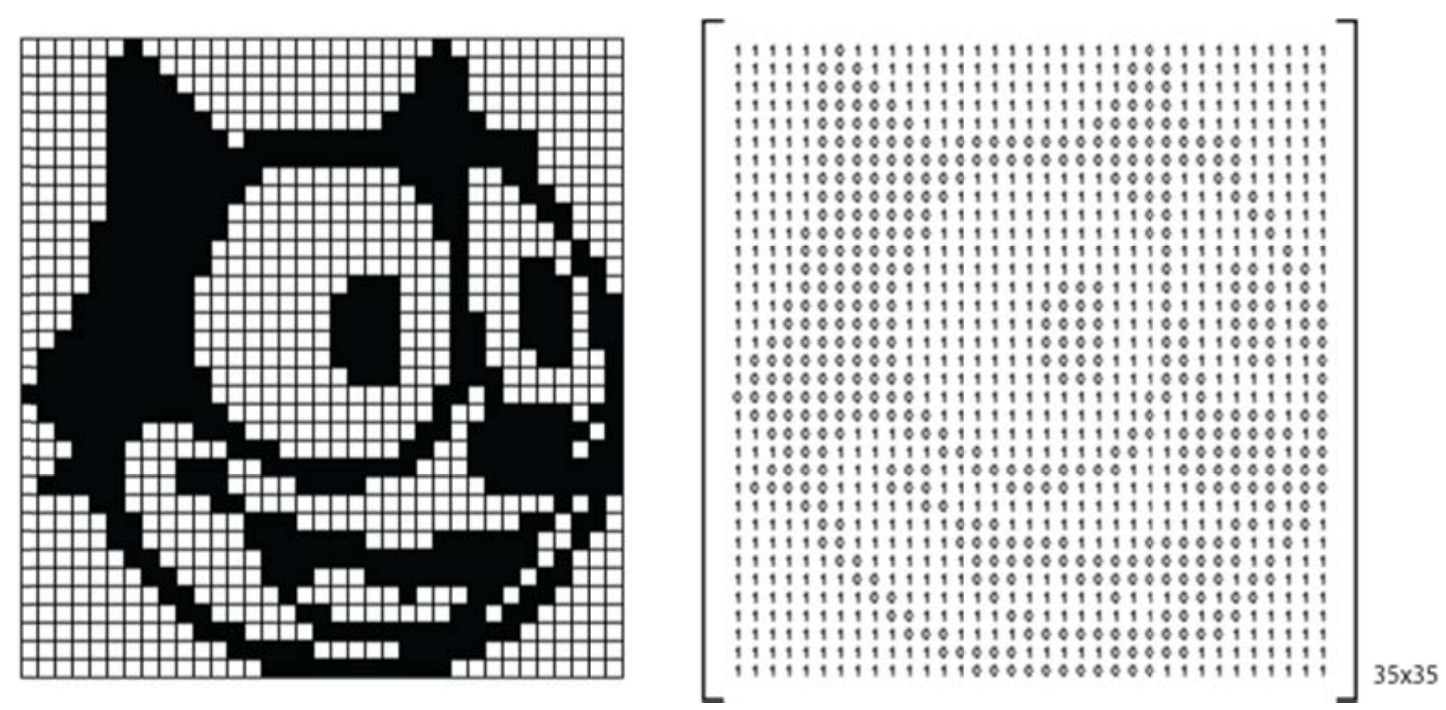

Figure 2. Felix and Matrix

Mathematics professors Humberto Jose Bortolossi and Dirce Uesu Pesco from Universidade Federal Fluminense in Brazil have been leaders in the exploration of teaching matrices 


\section{Macrothink}

International Research in Education

ISSN 2327-5499

2015, Vol. 3, No. 1

through images. Together, they have created applications to give students the opportunity to not only visualize images in their mathematical state, but also interact with the images provided. Such interaction gives students who are more visually minded a chance to see the transition between numbers and associated colors. Along with these applications, Bortolossi and Pesco have also incorporated a game called "The Game of Indices", which further connects the concept of matrix and image by asking students how matrix operations affect their corresponding images. The interactive applications can be found at http://www.uff.br/cdme/matrix/matrix-html/matrix_boolean/matrix_boolean_en.html

\subsection{Grayscale Images}

Grayscale images are depicted in a similar way to Boolean images. However, instead of using only 1 and 0 , each digital file input entry of the matrix displays an integer between 0 and 255 . This range indicates the level of intensity of the grayscale pixel. The numerical value of 0 represents minimal intensity, black, while 255 represents maximum intensity, white. This range between 0 and 255 reveals 256 integers, or levels of gray that could possibly be displayed in a pixel (Bortolossi and Pesco). Figure 3 displays multiple levels of gray along with their corresponding numerical values, ending in white (255) on the right.

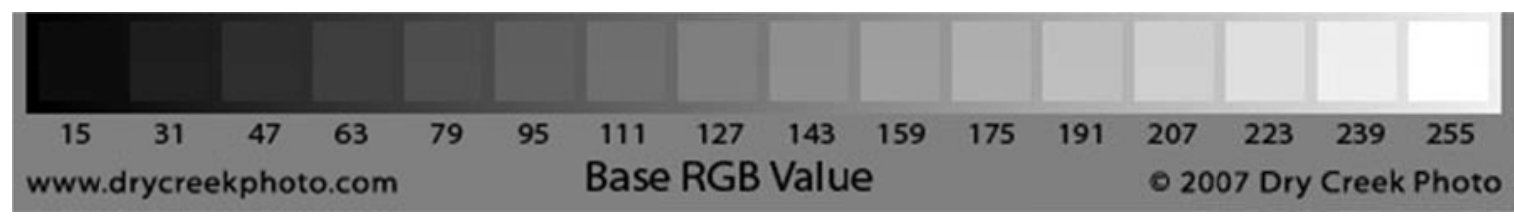

Figure 3. Greyscale

Bortolossi and Pesco have also created interactive applications to help give further visualization of the correspondence between matrices, gray scale values, and images which can be found at the following URL: http://www.uff.br/cdme/matrix/matrix-html/matrix_gray/matrix_gray_en.html

\subsection{The RGB Color Model}

For digital color images three matrices must be involved. Computers and camera capable cell-phones display images using the aforementioned RGB color mode. As mentioned before, RGB is an acronym for the primary colors of red, green, and blue used within the model and is based on color light wavelengths. To create any color within the RGB spectrum, a combination of three light beams of red, green, and blue must be used. The wavelengths of these light beams are added together to create the "light spectra" of a new color, thus RGB is called an "additive" color model (Poynton, 2003). Each RGB colored light beam is a component that can be represented by the numerical range of 0 to 255, and varies in intensity from being "fully on" to "fully off”. Zero (0) intensity results in black, or the lack of light, whereas full intensity (255) of an individual component displays the color in its most pure or saturated form. Using all three of the primary colors at the highest level of intensity creates 


\section{Macrothink}

International Research in Education

ISSN 2327-5499

2015, Vol. 3, No. 1

white, or "whole light" and is represented by the numerical values of $(255,255,255)$ (Boughen, 2003). The image in Figure 4 displays the three individual primary colored light beams of red, green, and blue, and how they mix together to form white light.

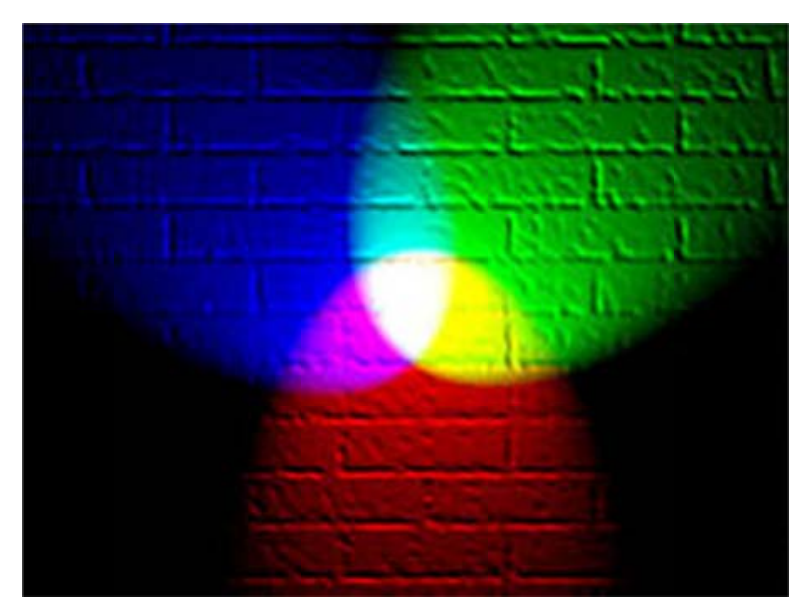

Figure 4. RGB Model

\subsection{Monochromatic images}

Color images as seen on an electronic screen can be split into three monochromatic, meaning 'containing or using only one color', images of red, green, and blue (Boughen, 2003). Figure 5 illustrates a color image that has been split into the three colors of red, green, and blue.
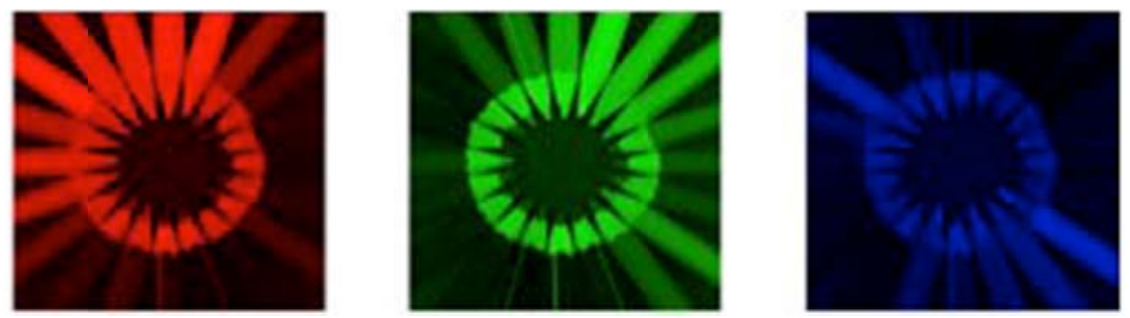

Figure 5. Monochromatic

A matrix, similar to the grayscale matrix discussed earlier, can represent each monochromatic image. The intensity of each pixel within one of these monochromatic images can be displayed as a number within the range of 0 and 255 (0, once again, represents black, while the value of 255 represents the purest form of the color: red, blue or green). The three monochromatic images of red, green, and blue create a full colored image. A matrix displaying numerical values between 0 and 255 makes up each monochromatic image. Thus, each full color image is created by three "monochromatic" matrices, layered on top of one another to represent the color of each individual pixel within the image. Each individual pixel 


\section{Macrothink}

International Research in Education

ISSN 2327-5499 2015, Vol. 3, No. 1

has three numerical values (or a 3 x 1 matrix - containing one value from each corresponding red, blue and green monochromatic pixel) to explain its hue structure. Figure 6 displays a familiar diagram from photo editing software depicting the monochromatic scales of red, green, and blue and their corresponding numerical values to create a color.

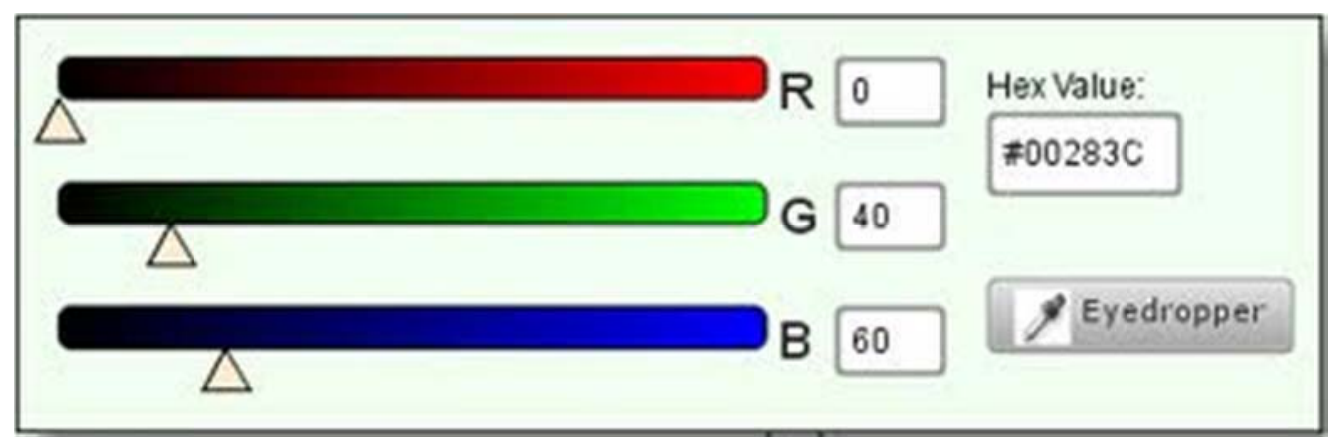

Figure 6. Photo Editing

If the numbers displayed in Figure 6 represented a single color pixel, the $3 \times 1$ matrix would display $(0,40,60)$ and the color pixel would be a dark blue hue. Figure 7 displays the Venn diagram of what RGB values contribute to the given color $(0,40,60)$.

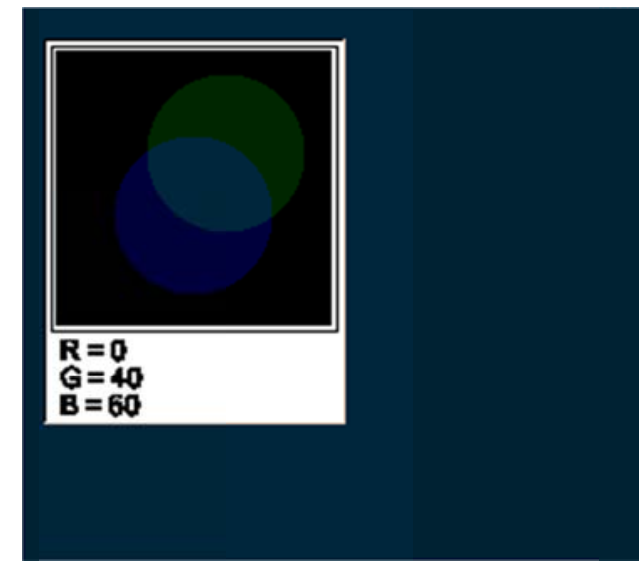

Figure 7. Venn

When layering images, pixel by pixel analysis is laborious. The question arises as to what the final layered image looks like if, for example, we layer the three monochromatic images. When layered, three images in Figure 5 form the images of Figure 8. 

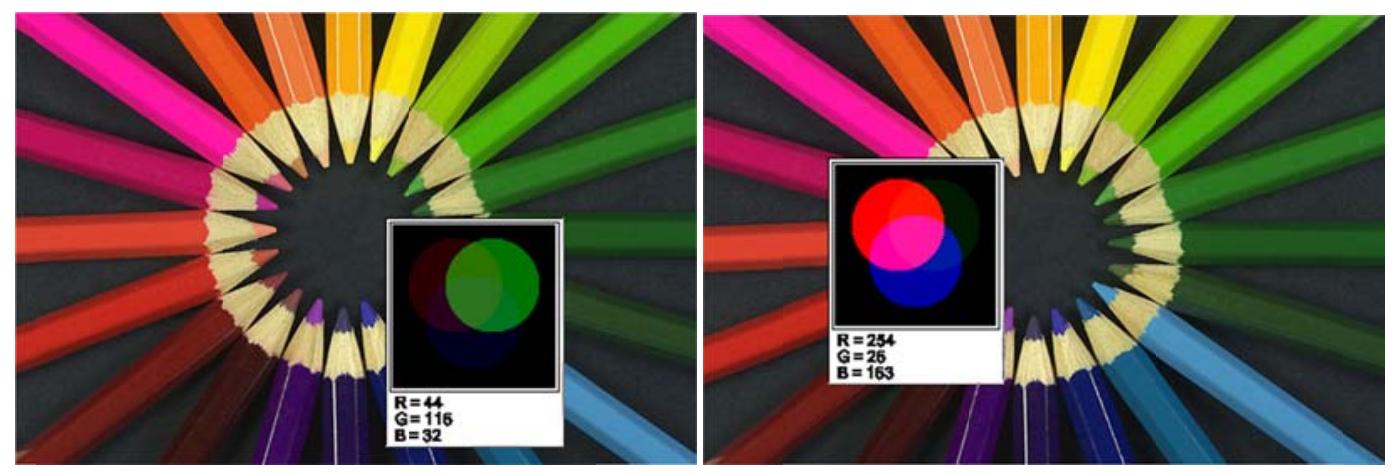

Figure 8. Layering

These full colored images are made up of many individual pixels, which all have a red, green, and blue value. The Venn diagrams display the intensity of red, blue and green within a specific pixel in the picture. The diagrams in Figure 8 describes a picture on the left within the pink pencil having the $3 \times 1$ matrix of $(254,26,163)$ and on the right, the diagram represents the matrix $(44,116,32)$ - that of a darker green. To see more images, numerical values and diagrams similar to those in Figure 8 , visit the website http://www.uff.br/cdme/matrix/matrix-html/matrix-en.html (Bortolossi and Pesco).

When editing colors of a digital image, each $3 \times 1$ pixel matrix is changed to create a new color. Often, adding new matrices to the existing pixel matrices within an image does this change. The sum of each individual input from the matrix additions all must be within the set of whole numbers $[0,255]$. Meaning that if the addition of the matrices creates inputs that are $<0$ or $>255$, the inputs are changed to be 0 and 255 respectively. Using this information, educators can present to their students matrix addition with a purpose in mind. For example, showing that to add colors in the matrix model "coordinate-wise", one could display the following example: $(0,0,128)+(128,0,0)=(128,0,128)$ and then show the colors accordingly on an RGB Color Code Chart such as the one that can be found at the following link: http://www.rapidtables.com/web/color/RGB_Color.htm. Using the tables provided from the Color Chart we can see that our example represents

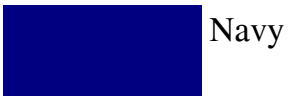

$+$

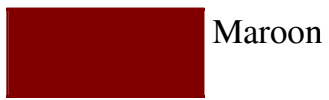

$=$

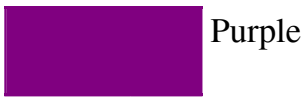

\#000080

\#800000

\#800080
$(0,0,128)$

$(128,0,0)$

$(128,0,128)$

Looking at Figure 9, and referring to the table and applications provided through rapid tables, students will be able to see the relationship between numbers and colors and will be able to mix accordingly. Using the following questions, teachers may make use of these ideas in the 
classroom:

a. Confirm that yellow plus blue makes blue white in the RGB model.

b. Confirm that yellow plus red makes yellow in the RGB model.

c. Confirm that yellow minus yellow equals black in the RGB model.

d. Confirm that orange minus red equals yellow in the RGB model.

e. Confirm that yellow minus red equals green in the RGB model.

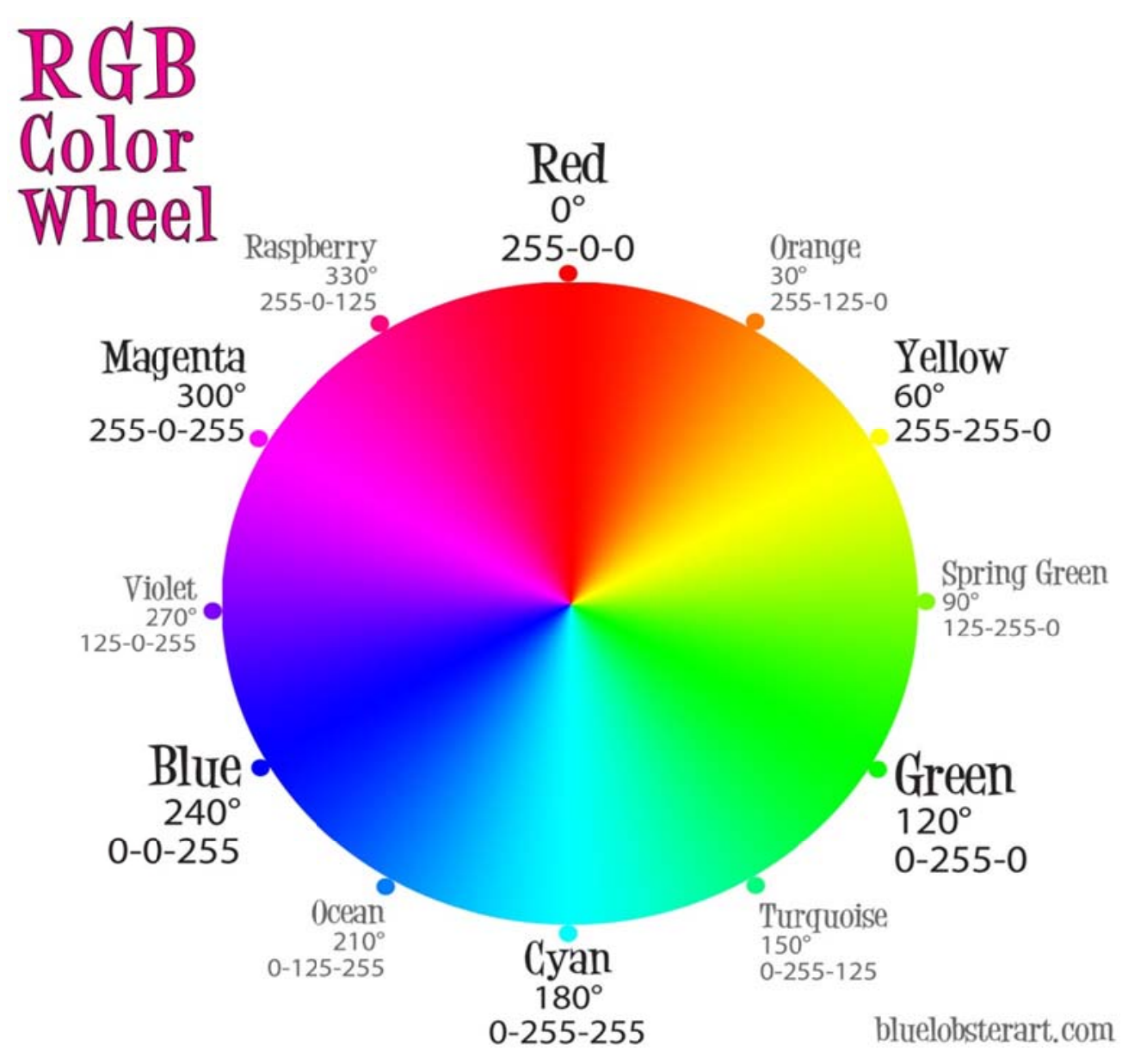

Figure 9. Color Wheel

\section{Conclusion}

Although it is often necessary to teach specific concepts and procedures, mathematics can be approached as a whole since many concepts and procedures, interrelated. Of all of the teaching reform recommendations being made by professional organizations such as the National Council of Teachers of Mathematics, making mathematical connections is among the more difficult to achieve, yet is so helpful in motivating students. Students are immersed in digital 
imagery on a daily basis with the growth of social media. Using students' interest in digital imagery to introduce matrices, teachers set the framework for a more in-depth analysis of matrices at the high school and collegiate levels. Through interactive applications such as those Bortolossi and Pesco have created, teachers can engage the mathematical interest of the ever-growing number of visual-spatial learners.

By using the connection between matrices and images, teachers have the opportunity to engage students through an artistic, visual approach while answering the age-old question, "When are we ever going to use this information?" These connections help students understand mathematics better and see it as a useful and interesting subject to study.

\section{References}

Bortolossi, H. J., \& Pesco, D. (n.d.). Matrices and Digital Images. Retrieved May 26, 2013, from http://www.uff.br/cdme/matrix/matrix-html/matrix-en.html

Boughen, N. (2003). LightWave 3D 7.5 Lighting. Plano, TX: Wordware Publishing.

Dry Creek Photo. (2007). Monitor Calibration Tests: Luminance Sensitivity. Retrieved May 26, 2013, from http://www.drycreekphoto.com/Learn/Calibration/monitor_sensitivity.html

Kruger Silverman, Linda. (2013). Visual-Spatial Learners. Gifted Development Center. Retrieved from http://www.gifteddevelopment.com/Visual_Spatial_Learner/vsl.htm

Lester, P. M. (2006). Syntactic Theory of Visual Communication. Retrieved May 26, 2013, from http://commfaculty.fullerton.edu/lester/writings/viscomtheory.html

Pederson, D. (2009). The RGB Color Wheel. Blue Lobster Art and Design. Retrieved May 26, 2013, from http://blulob.com/2009/03/08/the-rgb-color-wheel/

Poynton, C. (2003). Digital Video and HDTV: Algorithms and Interfaces. Amsterdam: Morgan Kaufmann.

Rapp, W. H. (2009). Avoiding Math Taboos: Effective Math Strategies for Visual-Spatial Learners. TEACHING Exceptional Children Plus 6.2, Retrieved May 26, 2013, from http://journals.cec.sped.org/tecplus/

\section{Copyright Disclaimer}

Copyright reserved by the authors.

This article is an open-access article distributed under the terms and conditions of the Creative Commons Attribution license (http://creativecommons.org/licenses/by/3.0/). 